\title{
An Animal-Assisted Intervention's Influence on Graduate Students' Stress and Anxiety Prior to an Examination
}

\author{
Christi Williams, Kristen Emond, Kara Maynord, Julie Simpkins, Allie Stumbo, Traci Terhaar \\ School of Physical Therapy, College of Health Sciences \& Nursing, Belmont University, Nashville, TN, USA \\ Email: christi.williams@belmont.edu
}

How to cite this paper: Williams, C., Emond, K., Maynord, K., Simpkins, J., Stumbo, A. and Terhaar, T. (2018) An Animal-Assisted Intervention's Influence on Graduate Students' Stress and Anxiety Prior to an Examination. Open Access Library Journal, 5: e4831.

https://doi.org/10.4236/oalib.1104831

Received: August 8, 2018

Accepted: September 16, 2018

Published: September 19, 2018

Copyright $\odot 2018$ by authors and Open Access Library Inc.

This work is licensed under the Creative Commons Attribution International License (CC BY 4.0).

http://creativecommons.org/licenses/by/4.0/ (c) (i) Open Access

\begin{abstract}
Introduction: Roughly $10 \%-30 \%$ of the United States' population is known to suffer from some form of anxiety. The majority of those who struggle with anxiety have their first experience before 21.5 years of age, which falls within the age range of many college students. Since stress and anxiety can lead to difficulty with concentrating and memory, they can have significant effects on a student's academic performance and success. One method of reducing stress and anxiety prior to high-stakes examinations is animal-assisted interventions (AAI). Methods: 39 graduate level students (12 males, 27 females) consented to participate in this study. Physiological stress levels were measured by gathering heart rate and blood pressure, and anxiety was measured using the State-Trait Anxiety Inventory (STAI). Baseline measurements were taken at times during the semester when students did not have exams in the near future. Measurements were repeated immediately before a practical examination following either an interaction with a registered therapy dog (experimental) or quiet time studying (control group). Results: A significant difference was observed on exam day between the control group and the experimental group on state anxiety $(P=0.008)$. No significant effects of the therapy dog were observed for heart rate, systolic blood pressure, or diastolic blood pressure $(P>0.05)$. Discussion and Conclusion: The results of this study indicate that interactions with a registered therapy dog may assist in reducing the anxiety of graduate students prior to a practical examination.
\end{abstract}

\section{Subject Areas}

Education, Nursing

\section{Keywords}

Animal-Assisted Intervention, Therapy Dog, Anxiety, Stress, Test Anxiety, 
Blood Pressure, Heart Rate, State-Trait Anxiety Inventory

\section{Introduction}

The prevalence of anxiety in the general population of the United States is noted to be $10 \%-30 \%$ [1], and of those individuals, $75 \%$ of them reported their first experience with anxiety before 21.5 years of age [2]. Given that the average age of onset for anxiety-related issues falls at a time when individuals may be pursuing a college or graduate-level degree, it is important to look for ways to help students manage their stress and anxiety [2] to assist in their ability to concentrate and recall information [1]. The terms stress and anxiety are commonly used interchangeably when they are different by definition, so it is important to understand each. Anxiety is defined as a "personality component involving cognitive, emotional, behavioral, and bodily reactions." [3]. One form of anxiety which many college students struggle with is test anxiety. Individuals with test anxiety may experience feelings of apprehension, panic, and thoughts of potential academic failure prior to or during an exam situation, which may lead to negative performance by deterring their mind from the task at hand [4]. Physiological stress on the other hand, refers to processes occurring within the body in response to an outside source that initiates a state of a real or perceived threat to homeostasis [4]. These threats activate the endocrine, nervous, and immune systems, which allow stress levels to be measured objectively [4]. Physiological markers of stress can be assessed by measuring salivary cortisol levels, neurohormone levels, and respiratory sinus arrhythmia, as well as heart rate and blood pressure [5] [6].

According to a study conducted by El-Ghoroury et al., more than $70 \%$ of graduate students report some type of stressor, which interferes with their optimal level of performance in daily life [7]. One of the biggest stressors university students undergo is written and practical examinations. Practical examinations are often required for many graduate degrees as a measure of a student's ability to perform advanced techniques and interactions through physical and oral means. These exams not only require understanding of concepts and information recall, they place great focus on the student's ability to answer questions critically and adapt to various situations that mimic their future career practice. As students progress to higher levels of education, exams have a greater impact on the attainment of a degree, as well as possible employment and scholarship opportunities. As a result, anxiety surrounding exams has become more common and often includes feelings of worry, apprehension, and even panic in regards to the possibility of failure [4].

A study conducted by Zhang et al. [8] aimed to determine a relationship between test anxiety and physiological stress as measured by changes in blood pressure and heart rate in sixty-four medical students $(20.0 \pm 0.1$ years old) [8] 
In evaluating medical students during an exam review and again during the exam periods, they observed a gradual increase in both blood pressure and heart rate from review day to exam day and determined that anxiety was the strongest influencing factor on heart rate and blood pressure, even ahead of family history of hypertension and smoking [8]. In agreeance with Zhang's article, one study found similar increases in blood pressure and heart rate in chiropractic students subjected to a clinical examination [9]. In this study, the chiropractic students also reported feelings of test anxiety and multiple physical symptoms, including nausea and headache [9]. Interestingly, the authors found that $23.3 \%$ of the students who experienced these physical symptoms also demonstrated increases in heart rate and blood pressure [9]. Further investigation showed that this group of students who appeared to be under high distress attained the lowest scores, demonstrating a negative relationship between exam stress and performance [9]. A study conducted by Zunhammer et al. [10] on college students aimed to observe the relationship between exam stress, psychological traits, and physical ailments with unknown etiology deemed to be somatic [10]. The researchers found that students' physical symptoms increased during exam periods, during which state anxiety (measured with the German STAI) and depression (measured with the German Beck's Depression Inventory II) were elevated [10]. The results indicated that students experienced a significant increase in somatic physical symptoms, such as headache, back pain, nausea, etc. during exam periods in which they were experiencing higher levels of anxiety and depression, which could not be accounted for by personality traits or pre-existing health conditions [10]. These findings highlight the importance of discovering ways to control exam-related stress and anxiety as it can adversely impact not only a student's psychological health, but also their physical health and overall performance.

Although there are many methods to reduce stress and anxiety, interacting with animals has become a valuable option when they have been properly trained. Therapy animals differ from service animals in that therapy animals are not trained in a specific task to accommodate a disability. Rather, therapy animals are trained and certified to provide affection and comfort to many people in different contexts. Animal-assisted interventions (AAI) use therapy animals to address factors such as stress and anxiety in the hopes of improving therapeutic gains [11]. When assessing the impact of AAI on adolescents in an inpatient facility, Bjick [12] noted that the patients found the animal-assisted intervention to be calming, and they felt less threatened by the unfamiliar people and overall setting [12]. Barker and Dawson [13] found that AAI had a similar effect on hospitalized psychiatric patients [13]. They compared a group of patients in a single animal-assisted therapy group session with those same patients in a single therapeutic recreation group session and found that anxiety in patients with psychotic disorders, mood disorders, and other disorders was significantly lower following the animal-assisted therapy group session compared to the normal 
therapeutic recreation group session [13]. Nepps et al. [14] also looked at the effects of an animal-assisted activity program on both psychological and physiological variables, including depression, anxiety, blood pressure, pulse, salivary cortisol, and pain in hospitalized psychiatric patients [14]. These variables were measured in an intervention group, who experienced an animal-assisted activity, and in a control group, who watched a stress management DVD. Both groups showed a decrease in depression, anxiety, pain, and pulse, which suggests that AAI appears to be as effective as other standard stress management interventions [14].

As previously mentioned, students are a part of the population who undergo a variety of stress-inducing factors, including the pressure of academic work that can be intensified during examinations. Several studies have found positive effects from the use of AAI in college students [15] [16] [17]. One study looked at stress levels in first year college students and found that students reported more positive feelings and fewer negative emotions after interacting with a therapy dog, compared to controls who engaged in low-energy activities like reading or listening to music [18]. In another study, students participated in an outreach activity where therapy dogs were used on campus as a counseling tool for students dealing with the stress of final exams [19]. Nearly 700 students completed pre- and post- surveys documenting self-reported stress levels, and the results indicated that $92.9 \%$ reported less stress after the event [19]. The students made comments such as, "Awesome experience and idea to reduce stress", and made requests for additional similar events [19]. These studies support further research into using animal-assisted interventions as a tool for coping with the pressures that graduate students experience.

Given the many benefits noted with animal-assisted interventions on college campuses, an interaction with a registered therapy animal may also reduce stress and anxiety in graduate-level students who are subjected to higher standards of performance and success in a practical examination testing format. The purpose of this study was to determine whether an interaction with a registered therapy dog would have a positive effect on the physiological stress markers of heart rate and blood pressure, as well as perceived anxiety in graduate-level students prior to a practical examination. It was hypothesized that doctoral-level students who underwent a 12-minute animal-assisted intervention prior to a practical examination would demonstrate a reduction in systolic blood pressure (SBP), diastolic blood pressure (DBP), heart rate (HR) and self-reported anxiety compared to a control group who did not receive an animal-assisted intervention.

\section{Materials and Methods}

\subsection{Subjects}

Researchers presented the details of this study to graduate professional students, who were then given the opportunity to take part if interested. Fifty doctor- 
al-level pharmacy and physical therapy students at Belmont University volunteered to participate in the study throughout the fall and spring semesters (October-March). All students read and signed an informed consent prior to baseline testing. Exclusion criteria were as follows: fear of dogs, allergy to pet dander, the inconsistent use of blood pressure or anxiety medications, and those under 18 years of age. The study was approved through the Belmont University IRB (Protocol \#151). Participation in this research was voluntary and subjects were free to discontinue participation at any time. Three subjects chose to withdraw within 24 hours of testing day without explanation, and five subjects failed to appear for their designated testing slot. Three subjects were excluded from the study due to inconsistent use of anxiety medication. A total of 39 participants remained in the study: 27 females and 12 males, ranging from 21 - 30 years of age (average age 24.42) following these exclusions.

\subsection{Baseline Measurements}

Subjects reported for baseline measurements of heart rate (HR), blood pressure (BP), and self-reported anxiety on one of several pre-scheduled days and times during the semester in which the class did not have an exam in another course. They were asked to refrain from any food or drink, with the exception of water, for one hour before testing. They completed both the state and trait components of the State-Trait Anxiety Inventory (STAI), a brief self-report measure consisting of statements about the individual's perceived anxiety [20]. Subjects selected a number on a scale of 1 to 4 to signify their level of agreeance with each statement both at that specific moment on the state anxiety component and in general on the trait anxiety component [20]. The scale is as follows: 1 representing "Very much so", 2 representing "Moderately so", 3 representing "Somewhat", and 4 representing "Not at all". The scores for each statement were added together for a total score, ranging from 20 - 80, with a higher score indicating greater anxiety [20]. Heart rate and blood pressure were taken using an automatic blood pressure cuff (Omron model BP786N), with the exception of three subjects who required a manual reading with a larger cuff (Omron Tru-Gage model).

\subsection{Exam Day Measurements}

All participants were asked to report to a designated on-campus classroom which was in close proximity to the practical examination location. They arrived approximately 35 - 40 minutes prior to their scheduled examination time to ensure that each subject had at least ten minutes to sit and relax prior to the intervention in an attempt to limit the effect of physical activity (i.e. walking or climbing stairs to get to the designated classroom) on HR and BP. The intervention itself lasted approximately 15 minutes, which included the 12-minute interaction with the therapy animal or quiet study time for the control group and additional time for paperwork completion. Each subject completed the interven- 
tion with at least ten minutes to get to the examination site to be certain that the intervention itself did not increase the subject's stress levels by placing them at risk of running late for their practical examination. Four local registered therapy dog teams were individually assigned to reserved rooms to act as the study's intervention. The dog teams were registered through Pet Partners, an organization dedicated to "improving human health and well-being through the human-animal bond." [21]. Pet Partners volunteers receive comprehensive coursework and are required to pass an in-person evaluation assessing the handler's proficiency and the animal's ability to demonstrate appropriate behavior in a variety of settings and scenarios [21]. Subjects were randomly assigned to either the control group or the experimental group and were escorted to the appropriate room based on their respective assignment. Both rooms were set up in order to maximize the student's comfort level. The experimental room was set up so that the subject had the option to sit with the dog either on a mat with blankets or in a chair next to the handler. The control room provided the option to sit on a mat with blankets or in a chair at a desk. Both groups were informed to engage in activities they normally would prior to a practical examination, including studying and reviewing exam material, regardless of their group assignment.

Control subjects were given the opportunity to engage in their normal pre-exam routine for 12 minutes. For some participants this meant independent studying, while for others it meant relaxing quietly. All control subjects were instructed not to engage in conversation with any other occupants in the room throughout the intervention.

Experimental subjects were allowed to interact with the registered therapy dog as they pleased, with the exception of active running and playing, which were discouraged due to their potential effect on heart rate and blood pressure. Activities included petting, brushing, holding, and/or talking to the dog. The experimental subjects were informed that they could also engage in their normal pre-exam routine, such as quiet studying, while interacting with the therapy dog. The therapy dog's handler was present in the room throughout the entirety of the experimental intervention and was instructed to avoid excessive conversation and interaction with the subject during the intervention.

Following the 12-minute control and experimental interventions, each subject's heart rate and blood pressure were measured prior to the individual standing up. Participants then completed the STAI for self-reported anxiety levels prior to exiting in time for their practical examination. All participants were given a post-participation questionnaire to provide feedback regarding their experience.

\section{Statistical Analysis}

Data are presented as mean \pm SD (shown in Table 1). IBM SPSS Statistics (version 23) was used to perform a two-way mixed analysis of variance (ANOVA). This was followed by independent and repeated measures T-tests to analyze 
simple effects of systolic blood pressure, diastolic blood pressure, heart rate, and anxiety as necessary. An independent T-test was performed to analyze trait anxiety between the control (no dog) and experimental (dog intervention) groups. It should be noted that the study consisted of $n=39$ subjects; however due to a missing data point for HR $(n=38)$, and the fact that two subjects did not fully complete the STAI $(n=37)$, the overall $n$ for the analyses below varies due to these factors. Significance in all tests was defined as $P<0.05$.

\section{Results}

\subsection{Systolic Blood Pressure}

A two-way mixed ANOVA revealed a significant main effect across time, increasing from baseline to exam day $(P=0.02, n=39)$. An interaction between group and time in systolic blood pressure $(P=0.001)$ was also observed. Post-hoc T-tests demonstrated that there was no significant difference between the groups at baseline, showing that the groups were homogeneous. A slight decrease was observed in the control group from baseline to exam day (124.8 \pm $12.45 \mathrm{mmHg}$ baseline to $122.95 \pm 12.42 \mathrm{mmHg}$ exam day, $n=20$; Table 1 ). However, the difference was not significant $(P=0.39)$, which indicates that it was likely due to chance. In contrast, there was a significant increase from baseline to exam day in the experimental group with exposure to the therapy dog intervention (119.00 $\pm 11.15 \mathrm{mmHg}$ baseline to $129.00 \pm 17.00 \mathrm{mmHg}$ exam day, $n$ $=19 ; P=0.02)$. However, despite the significant increase seen with the dog intervention, no significant difference was seen between the groups in exam day measures $(P=0.21)$ (see Table 2). This indicates that the dog intervention had no significant effect on systolic blood pressure.

\subsection{Diastolic Blood Pressure}

A two-way mixed ANOVA showed a main effect significant increase in diastolic blood pressure across time from baseline measures to exam day measures (79.82 $\pm 9.15 \mathrm{mmHg}$ baseline to $82.87 \pm 9.88 \mathrm{mmHg}$ exam day, $n=39 ; P=0.02$ ) overall when both groups were included. There was no significant main effect between groups $(P=0.99)$ and no significant interaction $(P=0.30)$. This indicates that the control group $(n=20)$ and the experimental group with the dog intervention

Table 1. Baseline and exam day measurements by group.

\begin{tabular}{|c|c|c|c|c|c|c|c|c|}
\hline & \multicolumn{4}{|c|}{ BASELINE MEASURES } & \multicolumn{4}{|c|}{ EXAM DAY MEASURES } \\
\hline & $\begin{array}{c}\mathrm{SBP} \\
\text { mean } \pm \mathrm{SD} \\
\mathrm{mmHg}\end{array}$ & $\begin{array}{c}\mathrm{DBP} \\
\text { mean } \pm \mathrm{SD} \\
\mathrm{mmHg}\end{array}$ & $\begin{array}{c}\mathrm{HR}, \\
\text { mean } \pm \mathrm{SD} \\
\mathrm{bpm}^{\mathrm{d}}\end{array}$ & $\begin{array}{c}\text { STAI, } \\
\text { mean } \pm S D\end{array}$ & $\begin{array}{c}\mathrm{SBP} \\
\text { mean } \pm \mathrm{SD} \\
\mathrm{mmHg}\end{array}$ & $\begin{array}{c}\mathrm{DBP} \\
\text { mean } \pm \mathrm{SD} \\
\mathrm{mmHg}\end{array}$ & $\begin{array}{c}\mathrm{HR}, \\
\text { mean } \pm \mathrm{SD} \\
\mathrm{bpm}^{\mathrm{d}}\end{array}$ & $\begin{array}{c}\text { STAI, } \\
\text { mean } \pm \mathrm{SD}^{\mathrm{e}}\end{array}$ \\
\hline Control & $124.8 \pm 12.45^{\mathrm{a}}$ & $80.45 \pm 8.17^{\mathrm{a}}$ & $73.75 \pm 12.92^{\mathrm{a}}$ & $\begin{array}{c}31.06 \pm \\
9.84^{\mathrm{c}, \mathrm{d}}\end{array}$ & $122.95 \pm 12.42^{\mathrm{a}}$ & $82.25 \pm 7.95^{\mathrm{a}}$ & $\begin{array}{l}85.6 \pm \\
16.44^{\mathrm{a}}\end{array}$ & $\underset{\mathrm{d}, \mathrm{e}}{47.39 \pm 13.69^{\mathrm{c}}}$ \\
\hline Experimental & $119 \pm 11.15^{\mathrm{b}, \mathrm{d}}$ & $79.16 \pm 10.27^{\mathrm{b}}$ & $73.72 \pm 11.59^{c}$ & $\begin{array}{c}33.79 \pm \\
9.38^{\mathrm{b}}\end{array}$ & $129 \pm 17^{\mathrm{b}, \mathrm{d}}$ & $\begin{array}{c}83.53 \pm \\
11.77^{\mathrm{b}}\end{array}$ & $86 \pm 9.44^{c}$ & $36.74 \pm 7.75^{\mathrm{b}, \mathrm{e}}$ \\
\hline
\end{tabular}


Table 2. P values of exam day comparisons between control and experimental groups.

\begin{tabular}{ll}
\hline Systolic blood pressure & $P=0.21^{\mathrm{a}}$ \\
Diastolic blood pressure & $P=0.69^{\mathrm{a}}$ \\
Heart rate & $P=0.93^{\mathrm{a}}$ \\
State anxiety & $P=0.008^{\mathrm{b}, \mathrm{c}}$ \\
\hline
\end{tabular}

${ }^{\text {a} P o s t-h o c ~ i n d e p e n d e n t ~ t-t e s t . ~}{ }^{\text {b}}$ Post-hoc Wilcoxon signed ranks test. ${ }^{\mathrm{C}}$ Indicates significance.

$(n=19)$ were not significantly different at either baseline or exam day (refer back to Table 1 for mean values). This result was confirmed with a post-hoc independent T-test between the two groups on exam day, which revealed no significance $(P=0.69)$ (see Table 2). Overall, the dog intervention had no significant effect on diastolic blood pressure.

\subsection{Heart Rate}

The two-way mixed ANOVA revealed a significant main effect increase in heart rate across both groups from baseline measures to exam day measures (73.74 \pm $12.14 \mathrm{bpm}$ baseline to $85.79 \pm 13.4 \mathrm{bpm}$ exam day, $n=38$; $P<0.001)$. No significant interaction effect was observed $(P=0.92)$, and there was no significant main effect between the control group and the experimental group with the dog intervention $(P=0.96)$. These indicate that the control group $(n=20)$ and the experimental group $(n=18)$ were not significantly different at either baseline or exam day (refer back to Table 1 for mean values). This result was confirmed with a post-hoc independent T-test between the two groups on exam day, which revealed no significance $(P=0.93)$ (see Table 2$)$, indicating that the dog intervention had no significant effect on heart rate.

\subsection{Anxiety (STAI)}

An independent T-test examining trait anxiety between the control group (39.67 $\pm 10.45, n=18)$ and the experimental group $(41.32 \pm 7.50, n=19)$ showed no significant difference $(P=0.58)$ between the groups. This revealed that the groups were similar in terms of overall trait anxiety and that one group was not significantly more anxious than the other prior to the intervention.

A significant increase in state anxiety levels was observed from baseline measures to exam day measures ( $32.46 \pm 9.57$ to $41.92 \pm 12.15$ on exam day, $n=37 ; P$ $<0.001)$ across all subjects in the two-way mixed ANOVA. In addition, a significant interaction was seen $(P=0.003)$. A post-hoc repeated measures T-test revealed a significant difference across time in the control group $(31.06 \pm 9.84$ at baseline to $47.39 \pm 13.69$ on exam day, $n=18 ; P<0.001)$. An independent T-test between the control group $(n=18)$ and the dog intervention experimental group $(n=19)$ showed a significant difference between the two $(P=0.008)$. The control group ( $47.39 \pm 13.69)$ was found to have significantly greater state anxiety on exam day than the experimental group $(36.74 \pm 7.75)$ (see Table 1$)$. This suggests that the dog intervention may have decreased state anxiety on exam 
day. A graphical representation of control and experimental group measurements on both days can be seen in Figure 1.

\subsection{Qualitative Results}

Subjective responses were also collected via post-participation questionnaires. Responses were given using a $1-10$ rating scale. In addition, space was provided for participants to explain further with an open-ended response. Table 3 shows that the majority of control group subjects, who did not experience the

Table 3. Post-participation questionnaire of control group (no dog, $n=15$ ).

\begin{tabular}{|c|c|c|c|c|c|c|c|c|c|c|}
\hline & 1 & 2 & 3 & 4 & 5 & 6 & 7 & 8 & 9 & 10 \\
\hline & $\begin{array}{l}\text { Not At } \\
\text { all }\end{array}$ & & & & Neutral & & & & & Significantly \\
\hline $\begin{array}{l}\text { To what extent do you think that an interaction would } \\
\text { have decreased your stress level prior to taking an } \\
\text { examination? }\end{array}$ & $0 \%$ & $0 \%$ & $0 \%$ & $5 \%$ & $5 \%$ & $20 \%$ & $35 \%$ & $25 \%$ & $5 \%$ & $5 \%$ \\
\hline $\begin{array}{l}\text { To what extent do you think that an interaction would } \\
\text { have increased your stress level prior to taking an } \\
\text { examination? }\end{array}$ & $45 \%$ & $25 \%$ & $15 \%$ & $5 \%$ & $10 \%$ & $0 \%$ & $0 \%$ & $0 \%$ & $0 \%$ & $0 \%$ \\
\hline $\begin{array}{l}\text { To what extent do you feel that an interaction would } \\
\text { have enhanced your performance on your examination? }\end{array}$ & $5 \%$ & $0 \%$ & $0 \%$ & $0 \%$ & $45 \%$ & $30 \%$ & $10 \%$ & $10 \%$ & $0 \%$ & $0 \%$ \\
\hline $\begin{array}{l}\text { To what extent do you feel that a Certified Therapy Dog } \\
\text { in a graduate program would benefit students? }\end{array}$ & $0 \%$ & $0 \%$ & $0 \%$ & $0 \%$ & $0 \%$ & $10 \%$ & $35 \%$ & $15 \%$ & $10 \%$ & $30 \%$ \\
\hline
\end{tabular}

Table 4. Post-participation questionnaire of experimental group (dog interaction, $n=13$ unless specified ${ }^{*}$ ).

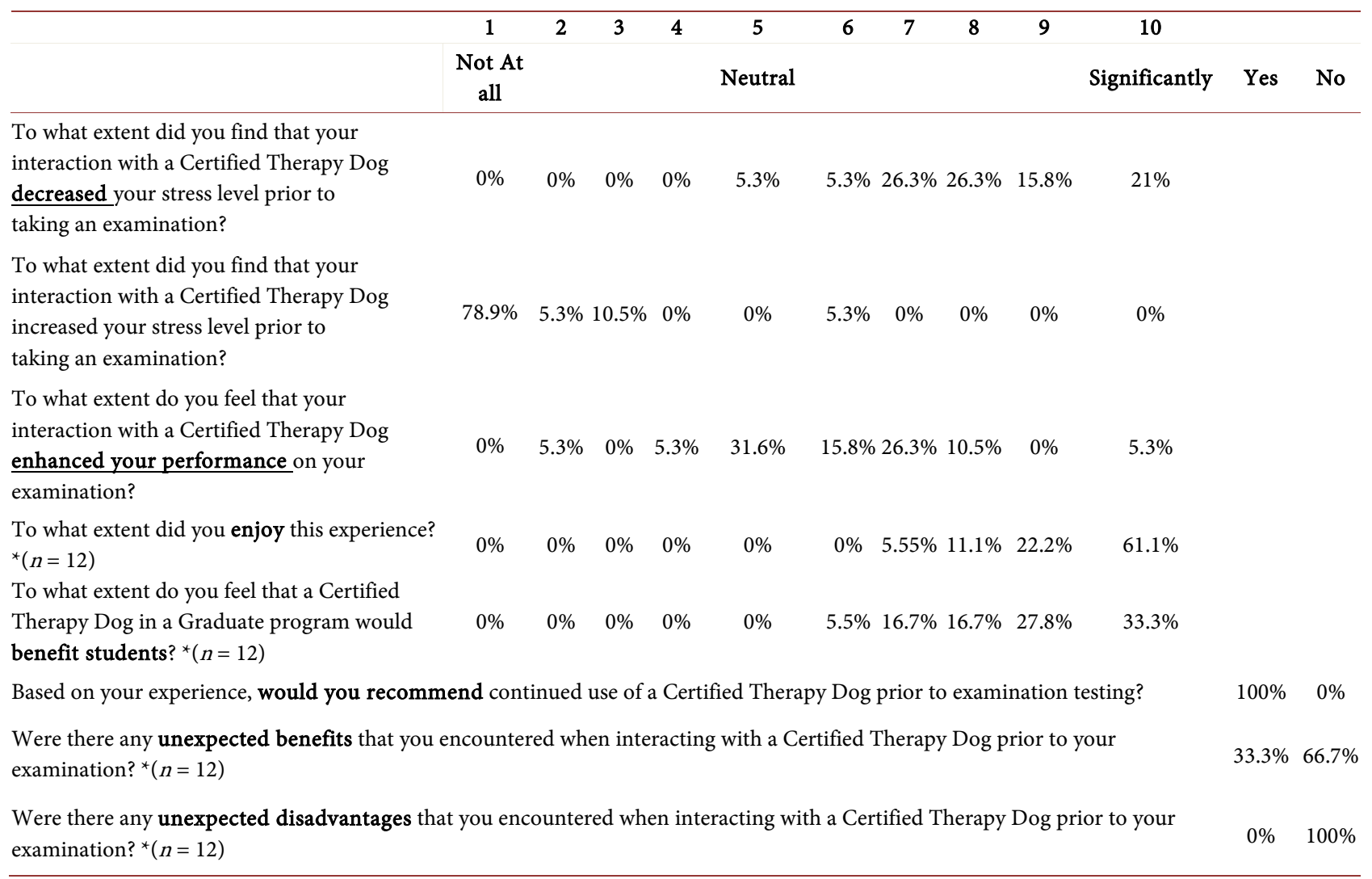




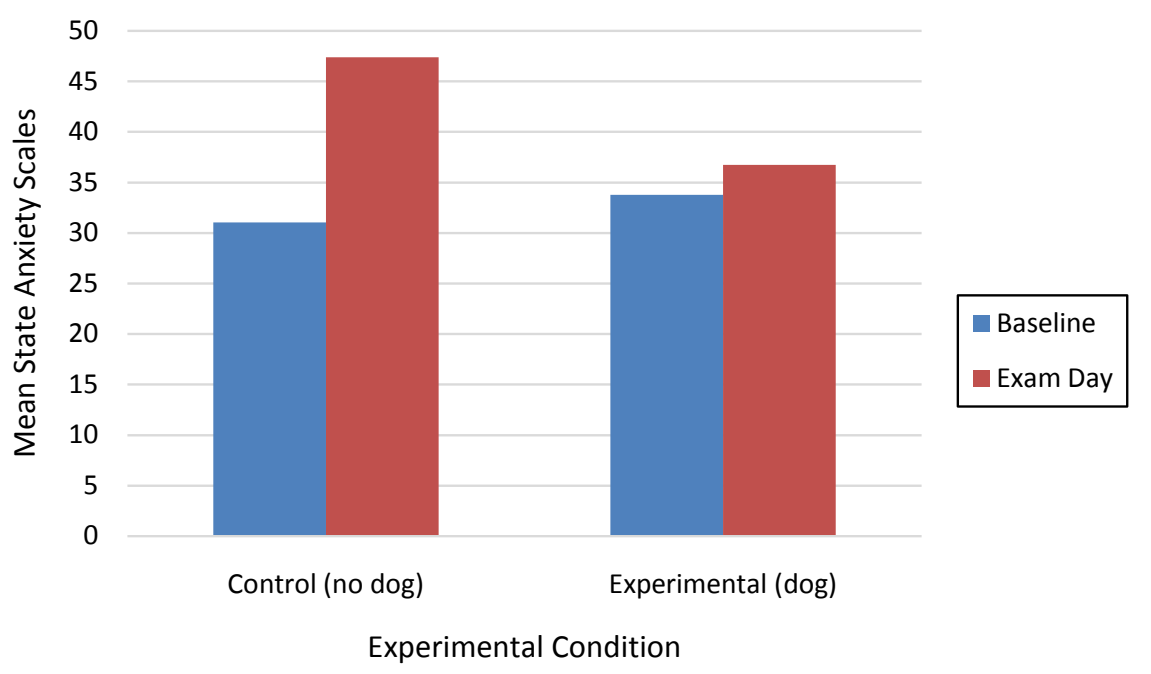

Figure 1. State Anxiety Level by Group.

registered therapy dog interaction, believed if they had experienced the interaction, it would have decreased their stress levels prior to taking their practical examination. On the scale of 1 to 10 (with 1 rated as not at all and 10 rated as significantly), $35 \%$ of subjects rated the extent that they believed a registered therapy dog interaction would have reduced their stress levels at a 7 out of 10 . Twenty-five percent believed that their stress levels would have reduced at a rating of 8 on the $1-10$ scale.

Subjects in the experimental dog intervention group reported the effect of the dog intervention to be even stronger than that predicted by the control group subjects, as seen in Table 4 . Over $26 \%$ of subjects in the experimental group rated a decrease in their stress due to the interaction with the registered therapy dog at a level of 8 on a scale of 1 to $10,15.8 \%$ rated the decrease in stress at a 9 , and $21 \%$ reported that the intervention decreased their stress at a level of 10 out of 10 . All of the subjects reported that the intervention decreased their stress levels to some extent, and while exam performance was not measured in this study, the majority reported that they felt the intervention somewhat enhanced their performance on their practical examination (see Table 4). In addition, $100 \%$ of the subjects stated that they would recommend the use of a registered therapy dog prior to examinations and that an inclusion of a registered therapy dog in their graduate program would benefit students.

\section{Discussion}

The purpose of our study was to determine the effects of an animal-assisted intervention on doctoral-level students prior to a practical examination with the hypothesis that AAI would reduce their stress and anxiety as measured by SBP, DBP, HR and STAI. The results of the study support the hypothesis that an interaction with a registered therapy dog significantly reduces self-reported state anxiety. In addition to the significant difference observed on the STAI, subjec- 
tive responses from the participants further supported the idea that the subjects viewed the therapy dog as a useful aid to combat anxiety before their practical examination. For example, a participant from the experimental group stated on the post-intervention questionnaire, "My stress levels typically fluctuate in the couple of hours leading up to lab practicals, but being able to interact with the therapy dog made those fluctuations level out a bit more leading up to testing. It was nice to go into the exam with a calmer attitude than I am usually accustomed to."

Despite the positive findings for a reduction in state anxiety, the results of this study did not support the hypothesis that an interaction with a therapy dog would reduce physiological measures of stress as measured by blood pressure and heart rate. Blood pressure is commonly associated with and greatly influenced by a human's anxiety level [8]. The results from our study showed that there was no significant change in SBP of the control group, and there was a significant increase in SBP of the experimental group from baseline to exam day. Despite this increase, no significant difference was found between groups on exam day, leading to the conclusion that the dog intervention did not have a significant influence on SBP. Although our hypothesis regarding blood pressure was not supported, there have been multiple instances in the literature that may explain the SBP increase seen in the experimental group. A study conducted by Crump and Derting [18] looked at the effect of animal-assisted therapy in female undergraduate freshmen. They found an increase in SBP in the animal-assisted therapy group, which they concluded could likely be due in part to an emotional response, leading to greater psychological and physiological arousal [18]. Given this, it is possible that the increase in SBP observed in the experimental group in this study could be explained by the subjects' emotional response to the dog. It is also possible that significance may have been achieved if our study's intervention had lasted longer than 12 minutes, as Marcus et al. [22] reported that BP in adults significantly reduced after interacting with a therapy dog, but that the changes happened after an average of 15 minutes (within a range of $5-24 \mathrm{mi}-$ nutes) [22]. Regarding DBP, no significant results were noted over time from baseline to exam day or between groups, indicating the dog had no significant effect on that measure.

Along with blood pressure, Zhang et al. reported that an increase of heart rate is strongly correlated with increased anxiety [8]. Heart rate results in this study showed a trend similar to blood pressure in that there were no significant differences between groups on exam day. However, a significant increase in HR was observed overall from baseline to exam day, demonstrating that both groups experienced a fairly equal increase. This is likely a reflection of the natural anxiety of all participants on a stressful exam day. While other studies have found reductions in HR with animal-assisted interventions [14] [17], Kaminski et al. [23] conducted a study in a pediatric hospital setting testing several variables, including heart rate, with animal-assisted therapy interventions and found HR 
to be significantly higher in the animal-assisted therapy group than the child-life group, which consisted of open play. The authors noted that the increase in HR was most likely due to anticipatory excitement of being with the animals [23]. This suggests that similarly to blood pressure, an emotional response, namely excitement of being with the therapy dog, could have led to an increase in HR rather than a decrease as was predicted.

One of the most clinically relevant outcomes of the study was the measure of anxiety using the STAI. The STAI is a widely used tool for determining self-reported anxiety and has well-established reliability, validity, and sensitivity for detecting changes in anxiety during periods as short as 10 - 30 minutes [20]. In our study, the STAI results provide the greatest support for using AAI prior to practical examinations. No difference in trait anxiety was observed, indicating that the groups were homogenous, and neither involved a greater number of subjects with higher naturally occurring anxiety. State anxiety levels increased in all subjects from baseline to exam day, but they only significantly increased in the control group. There was also a significant difference between groups on exam day, where the control group showed greater state anxiety than the therapy dog intervention group, as recorded in Table 1. These findings would suggest that the presence of the dog decreased feelings of anxiety in the experimental group, further supported by one participant's subjective response stating, "I was feeling very anxious, nervous, and stressed about my upcoming practical before I walked in, but Swoosh (registered therapy dog) really helped me relax as I spent time petting and playing with him." In a similar manner, Cole et al. [6] observed state anxiety in 76 subjects divided between an animal-assisted therapy group, a volunteer group, and a usual-care group [6]. They found a significant reduction in state anxiety, as measured with the STAI, from baseline to intervention in the animal-assisted group, but not the other groups [6].

Numerous past studies have demonstrated the ill effects of high levels of anxiety and, more specifically, test anxiety in students. As Zhang et al. [9] found, there is a correlation between higher test anxiety and poorer performance on examinations. Furthermore, Zunhammer [10] reported that students experience an increase in somatic physical symptoms including headaches, nausea, and loss of appetite during periods of increased exam anxiety [10]. Our findings suggest that an AAI could be useful in reducing graduate students' anxiety prior to their high-stakes practical examinations. In turn, this could help improve performance on said examinations, as supported by the open-ended responses of multiple subjects in this study. One student stated, "Being able to go into the lab practical without as much stress/anxiety definitely made me more level-headed during the practical. Even on the one occasion where I initially stated incorrect nerve roots, I was able to catch my mistake and correct myself immediately. I don't know if I would have been able to recognize my mistake if I walked in as stressed as I was for the first practical." In addition, an AAI prior to examinations could help reduce somatic symptoms and improve students' overall 
well-being.

\subsection{Limitations of This Study}

A major limitation of this study was the small number of subjects, partly due to the high percentage of subjects who dropped out or were excluded from data analysis $(22.0 \%)$. The small sample reduces the ability to observe significant differences between groups and generalize results to a larger population. More importantly is the fact that a number of participants withdrew from the study or did not appear for their designated testing slot on exam day. It is possible that they may have been more anxious about the upcoming exam and felt that they did not have time to participate in the study. If those who remained in the study were not as anxious about the exam, it may have skewed the results. Another limitation involved the four dog therapy teams that interacted with the experimental group. While the teams were instructed not to engage with the subjects excessively, there may have been a difference in the amount of interaction provided from the dog handlers that could have affected the stress and anxiety measures of the subjects differently. Finally, although the STAI has been proven to be both reliable and valid, it is subjective in nature and remains a limitation. It is possible that any bias toward believing that the dog interaction would decrease anxiety could have influenced participants' responses.

\subsection{Future Research Directions}

While our study shows a promising effect of animal-assisted intervention on anxiety in graduate students, further research is required in order to support its use in professional graduate programs. Future research could examine the option of obtaining both baseline and intervention measurements on different examination days so that any significant difference could be more confidently attributed to the presence of the therapy dog. It may also be beneficial to examine the test performance of each participant to provide greater information on how stress and anxiety may affect student exam scores. Alternatively, future research could divide subjects into three groups: a control group, a group with a friendly person intervention, and a group with a registered therapy dog and handler team. This could examine whether any effects are the result of the interaction with the dog or may be due to the handler's presence. Finally, another aspect that should be explored is when the effects of the dog interaction are greatest. Taking measurements at various time intervals during or after the interaction could demonstrate the most optimal time that anxiety is lowered by interaction with the dog.

\section{Conclusion}

Overall, our results support further research into using animal-assisted interventions to decrease anxiety and, more specifically, test anxiety in graduate students. Examinations are a major causative factor of stress and anxiety in students, and they are likely to be more demanding in the graduate school environment. Any 
negative physiological changes of stress or subjective feelings of anxiety could obstruct a student's performance, misrepresenting knowledge they have gained. Poor test performance could ultimately affect their future regarding scholarships or job opportunities. Stress and anxiety can be detrimental not only to students' performance during their time in graduate school, but also to their health. Therefore, determining methods of reducing anxiety in the graduate student population is necessary, and AAI is clearly one option that should be considered more often.

\section{Conflicts of Interest}

The authors declare no conflicts of interest regarding the publication of this paper.

\section{References}

[1] Sakin, O.N., Ercan, I., Irgil, E. and Sigirli, D. (2010) Anxiety Prevalence and Affecting Factors among University Students. Asia Pacific Journal of Public Health, 22, 127-133. https://doi.org/10.1177/1010539509352803

[2] Marazziti, D., Ambrogi, F., Abelli, M., et al. (2007) Lymphocyte Subsets, Cardiovascular Measures and Anxiety State before and after a Professional Examination. Stress, 10, 93-99. https://doi.org/10.1080/10253890601170563

[3] Sarason, I.G. (1984) Stress, Anxiety, and Cognitive Interference: Reactions to Tests. Journal of Personality and Social Psychology, 46, 929-938. https://doi.org/10.1037/0022-3514.46.4.929

[4] Lawson, D.J. (2006) Test Anxiety: A Test of Attentional Bias. Electronic Theses and Dissertations, 38. http://digitalcommons.library.umaine.edu/etd/38

[5] Ghazali, D.A., Ragot, S., Breque, C., et al. (2016) Randomized Controlled Trial of Multidisciplinary Team Stress and Performance in Immersive Simulation for Management of Infant in Shock: Study Protocol. Scandinavian Journal of Trauma, Resuscitation and Emergency Medicine, 24, 1-12.

https://doi.org/10.1186/s13049-016-0229-0

[6] Cole, K.M., Gawlinski, A., Steers, N. and Kotlerman, J. (2007) Animal-Assisted Therapy in Patients Hospitalized With Heart Failure. American Journal of Critical Care, 16, 575-588.

http://go.galegroup.com.bunchproxy.idm.oclc.org/ps/i.do?\&id=GALE|A171139138 \&v=2.1\&u=tel_a_belmont\&it=r\&p=AONE\&sw=w\#

[7] El-Ghoroury, N.H., Galper, D.I., Sawaqdeh, A. and Bufka, L.F. (2012) Stress, Coping, and Barriers to Wellness among Psychology Graduate Students. Training and Education in Professional Psychology, 6, 122-134. https://doi.org/10.1037/a0028768

[8] Zhang, Z., Su, H., Peng, Q., Yang, Q. and Cheng, X. (2011) Exam Anxiety Induces Significant Blood Pressure and Heart Rate Increase in College Students. Clinical and Experimental Hypertension, 33, 281-286. https://doi.org/10.3109/10641963.2010.531850

[9] Zhang, N. and Rabatsky, A. (2015) Effects of Test Stress during an Objective Structured Clinical Examination. The Journal of Chiropractic Education, 29, 139-144. https://doi.org/10.7899/JCE-14-17

[10] Zunhammer, M., Eberle, H., Eichhammer, P. and Busch, V. (2013) Somatic Symptoms Evoked by Exam Stress in University Students: The Role of Alexithymia, 
Neuroticism, Anxiety and Depression. PLoS One, 8, 1-11. https://doi.org/10.1371/journal.pone.0084911

[11] Linder, D.E., Siebens, H.C., Mueller, M.K., Gibbs, D.M. and Freeman, L.M. (2017) Animal-Assisted Interventions: A National Survey of Health and Safety Policies in Hospitals, Eldercare Facilities, and Therapy Animal Organizations. American Journal of Infection Control, 45, 883-887. https://doi.org/10.1016/j.ajic.2017.04.287

[12] Bjick, M. (2013) The Effects of a Therapy Animal on College Student Stress and Arousal. Master of Social Work Clinical Research Papers, 152. http://sophia.stkate.edu/msw_papers/152

[13] Barker, S.B. and Dawson, K.S. (1998) The Effects of Animal-Assisted Therapy on Anxiety Ratings of Hospitalized Psychiatric Patients. Psychiatric Services, 49, 797-801. https://doi.org/10.1176/ps.49.6.797

[14] Nepps, P., Stewart, C.N. and Bruckno, S.R. (2014) Animal-Assisted Activity: Effects of a Complementary Intervention Program on Psychological and Physiological Variables. Journal of Evidence-Based Complementary \& Alternative Medicine, 19, 211-215. https://doi.org/10.1177/2156587214533570

[15] Stewart, L.A., Dispenza, F., Parker, L., Chang, C.Y. and Cunnien, T. (2014) A Pilot Study Assessing the Effectiveness of an Animal-Assisted Outreach Program. Journal of Creativity in Mental Health, 9, 332-345. https://doi.org/10.1080/15401383.2014.892862

[16] Young, J.S. (2012) Pet Therapy: Dogs De-Stress Students. Journal of Christian Nursing, 29, 217-221. https://doi.org/10.1097/CNJ.0b013e31826701a7

[17] Polheber, J.P. and Matchock, R.L. (2013) The Presence of a Dog Attenuates Cortisol and Heart Rate in the Trier Social Stress Test Compared to Human Friends. Journal of Behavioral Medicine, 37, 860-867. https://doi.org/10.1007/s10865-013-9546-1

[18] Crump, C. and Derting, T.L. (2015) Effects of Pet Therapy on the Psychological and Physiological Stress Levels of First-Year Female Undergraduates. North American Journal of Psychology, 17, 1-14.

http://link.galegroup.com.bunchproxy.idm.oclc.org/apps/doc/A435796037/HRCA? $\underline{\mathrm{u}=\text { tel_a_belmont\&sid=HRCA\&xid=edfd8a9b }}$

[19] Barker, S.B., Barker, R.T. and Schubert, C.M. (2017) Therapy Dogs on Campus: A Counseling Outreach Activity for College Students Preparing for Final Exams. Journal of College Counseling, 20, 278-288. https://doi.org/10.1002/jocc.12075

[20] Spielberger, C., Gorsuch, R., Lushene, R., Vagg, P. and Jacobs, G. (1983) State-Trait Anxiety Inventory for Adults. Mind Garden, Menlo Park, 1-33.

[21] Pet Partners. Our Therapy Animal Program Website. http://petpartners.org/volunteer/our-therapy-animal-program/

[22] Marcus, D.A. (2013) The Science behind Animal-Assisted Therapy. Current Pain and Headache Reports, 17, 322. https://doi.org/10.1007/s11916-013-0322-2

[23] Kaminski, M., Pellino, T. and Wish, J. (2002) Play and Pets: The Physical and Emotional Impact of Child-Life and Pet Therapy on Hospitalized Children. Child Heal Care, 31, 321-335. https://doi.org/10.1207/S15326888CHC3104_5 